University of Nebraska - Lincoln

DigitalCommons@University of Nebraska - Lincoln

To Improve the Academy

Professional and Organizational Development Network in Higher Education

1994

Leveling the Playing Field

Linda Hilsen

Deborah Petersen-Perlman

Follow this and additional works at: https://digitalcommons.unl.edu/podimproveacad

Part of the Higher Education Administration Commons

Hilsen, Linda and Petersen-Perlman, Deborah, "Leveling the Playing Field" (1994). To Improve the Academy. 308.

https://digitalcommons.unl.edu/podimproveacad/308

This Article is brought to you for free and open access by the Professional and Organizational Development Network in Higher Education at DigitalCommons@University of Nebraska - Lincoln. It has been accepted for inclusion in To Improve the Academy by an authorized administrator of DigitalCommons@University of Nebraska - Lincoln. 


\section{Leveling the Playing Field}

\section{Linda Hilsen}

\section{Deborah Petersen-PerIman}

University of Minnesota, Duluth

To promote equity in education the authors contend that teachers must: 1) hear all the voices in their classrooms, 2) distribute power so students can vocalize, 3) establish ground rules with students on how to interact in the classroom, and 4) use active teaching and learning strategies in their classrooms. By employing each of these four strategies, the authors believe the educational playing field will become level, enabling all to participate equitably in attaining educations.

In "Sexism in the Classroom: From Grade School to Graduate School," Myra and David Sadker suggest that "classrooms [are] characterized by a more general environment of inequity" (1990, p. 10). Simply put, in the classroom, teachers treat students as either the "haves" or "have nots." Ten percent of the students in a classroom have the opportunity to be interaction rich, the stars. The Sadkers point out that "bias in classroom interaction inhibits student achievement" (p. 10). Certainly that is not what teachers want for the majority of their students. If teachers level the playing field by following established ground rules and employing active teaching practices, all students will be enabled to participate, to have their voices heard, and to be contributing members of an educational team.

In this article, the authors begin by addressing the need for all voices to be heard. This can be accomplished if the coach teaches the players how to play the game and the teacher relinquishes some control and empowers the students. A discussion on the distribution of power 
and the establishment of ground rules for class discussion composes the second section of the article. Finally, the authors identify a number of active teaching and learning strategies designed to let all players in the classroom participate equitably.

\section{Hearing All the Voices and Distributing Power}

Faculty need to relinquish a bit of their authority to create an oppression-free learning environment in which the varied voices of all students-regardless of age, race, gender, national origin, religion, sexual orientation, class, and/or able-bodiedness - can be heard. Although Catherine G. Krupnick's work is focused on gender issues, it can be applied more broadly to combatting the 'isms of the 1990 s. Krupnick, author of "Women and Men in the Classroom: Inequality and Its Remedies," reports on a year-long study of the communication patterns in 24 different Harvard classrooms. She relates that in the predominant classroom circumstance in coeducational higher education institutions (a male teacher with a majority of male students), males speak two-and-a-half times longer than their female peers $(1985$, p. 18). A bit of good news is that female instructors seem to inspire female students; the study shows that women speak three times longer in classes led by females. However, the study indicates that in no mix of genders among teachers and students do women students speak as much as men in coeducational settings. Men dominate mixed discussion in and out of the classroom (p. 19). It seems reasonable to infer that a broader range of instructors, representing more and different kinds of people, might serve to encourage participation among students. But, it is imperative that all instructors, regardless of who they are, become consciously aware of the kinds of communication patterns they have been using and how those patterns influence the way they interact with students. Awareness of the behaviors teachers use can lead to acknowledgement of how those behaviors can stifle or encourage students in their classrooms.

To make coeducation equal education, faculty must develop an awareness of how male and female speech patterns have been culturally acquired which may well be due to power imbalances in society (Parlee, 1989). Again, the case of gender can be applied more broadly 
to concerns regarding race, ability, sexual orientation, and so forth. Faculty need to aid many different students in developing fluency and eliminating verbal hesitancy in the classroom. Teachers must bring to a conscious level-for themselves and for their students-women's and other minority members' tendency to underparticipate in a white, male-dominated classroom. All students need equal opportunity to express themselves in order to internalize content and practice inquiry styles. Instructors have the power to facilitate growth, to create opportunities for equal education; hearing all the voices should be a major thrust in teaching, regardless of one's academic discipline.

The teacher has to structure equality into the classroom, not just through communication patterns, but also through the choice of teaching mode, the structuring of exercises, and the questioning strategies used. Teachers should intentionally structure interactive activities so students have opportunities to think on their own. For example, teachers might ask students to reflect on questions posed by first writing down their own thoughts, talking with other students, and then engaging in broader class discussion. An exercise designed like this is more likely to engender active student involvement in class discussion; students are much more likely to make comments when they feel more confident about what they want to say because they have first clarified their thoughts in writing and in a small group setting. Expressing ideas in comfortable, nonintimidating situations builds students' self-esteem. To reiterate, not only is it essential to be consciously aware of communication patterns being fostered in the classroom, it is likewise essential to be aware that creating an equitable playing field is directly related to power distribution, teaching mode, and questioning strategies.

All instructors need to reflect on their power distribution in the classroom. The authority figure, the teacher, is the possessor of power in the classroom, unless she chooses to be otherwise. A learning environment in which all voices are heard on a regular basis can be consciously designed. But to do this, the teacher must relinquish some power by being a teacher, not a teller; the teacher must empower students. Through self-reflection and interaction with an instructional development consultant or trusted colleague, the teacher can assess the degree of control being maintained in the classroom. In many 
instances, the more power given away, the easier it is for students to learn. Providing opportunity for verbalizing assists students in internalizing knowledge and inquiry methods.

Examining the case of gender further, Krupnick's study isolates four factors which decrease women's access to discourse: 'their demographic status as members of a minority in the classroom; their inability or unwillingness to compete against men; their vulnerability to interruption; and the fact that men and women talk in runs, which tends to keep female participation low" (1985, p. 21). The runs referred to are extensive periods of predominantly male talk followed by short spurts of all-female talk, with lots of females' comments overlapping. The tapes in the Harvard-Danforth study give evidence that women, not male students or authority figures, most often interrupt other female students (p. 20). Instructors need to help the voiceless be heard by monitoring power distribution in the classroom.

\section{Agreeing on Ground Rules: Establishing Rules of Play}

One way to create a more equitable classroom is to set up ground rules on the first day of class. As Lynn Cannon points out, "If learning is to take place, it may well be best if privileged groups listen more than talk, and others talk more than usual" (1990, p. 129). Cannon suggests establishing ground rules for class discussion to help redistribute the power and create a safe environment for open discussion. Although the rules are most effective when student discussion generates the agreed upon ground rules, a paraphrased version of Cannon's ground rules, which follows, will help instructors guide a class in creating its own rules:

- Discrimination exists in many forms (e.g., sexism, racism, classism, ageism, homophobia, antisemitism, ableism, etc.).

- Any critical understanding of these various 'isms means we need to recognize that we have been taught misinformation about our own group as well as about members of other groups. This is true for both dominant (e.g., white, male, upper class, heterosexual, able-bodied, etc.) and subordinated (e.g., people of color, women, 
poor, working class, gay/lesbian, disabled, Jewish, etc.) group members.

- We cannot be blamed for misinformation we have learned.

- People and groups are not to be blamed for their subordinate positions.

- People are always doing the best they can.

- We must actively pursue information about our own groups and those of others. We must share information about our own groups with other members in the course but never demean, devalue, or in any way put down people for their experiences.

- We each have an obligation to actively combat the myths and stereotypes about our own groups and other groups so that we can break down the walls which prohibit group cooperation and group gain.

The ground rules should be unique to each classroom, emerging from interaction between teacher and students. Once the rules have been agreed upon, it becomes clear that taking the time away from content to reach consensus over the rules of the game yields rich rewards in the quality and distribution of student contributions.

The classroom is not an ordinary public forum. It is a restricted environment. This is not to say that it should be a restrictive environment; rather, it should be a responsible one, and that implies certain rules and obligations which structure the class. Teachers have an obligation to create a safe milieu for learning. The ground rules are designed to do just that.

The essence of these ground rules is to establish an atmosphere of mutual respect. Those individuals who may not be a part of a mainstream power base need to know they are valued. An ideal is to engage all students in the classroom. This cannot happen if certain students in the course are cast in the role of "other" or "outsider" by virtue of classroom topics or discussion. When, through the use of epithets or stereotypical myths students are identified as not being like everyone else, there is a danger they will be shut out of classroom activities. By asserting the need for mutual respect, instructors and students embrace the differences that exist in society and also in classes. More and further-reaching discussion is propelled by welcoming diversity. If 
students feel that they are comfortable enough, safe enough to participate that their participation is welcomed and valued, better communication and hence greater learning will occur.

Professors use powerful words, and there is always a risk that teachers will intimidate students simply by entering the classroom. The professor, automatically, is assigned a role of authority and thus appears to have tremendous power. It is absolutely necessary for the professor to discuss the ground rules with the students. Each person must understand the responsibilities he or she has. Often, while discussing these rules, students resist the idea that certain words should be squelched. It is important that all students in the classroom know where the others stand so they can argue more effectively and constructively with each other and arrive at a place closer to that unattainable ideal - truth. The object of the ground rules is to restrict name-calling, not discussion of ideas. This is an absolutely vital distinction. The Supreme Court, although rejecting the concept of hate crimes, has recognized "fighting words" as unprotected by the First Amendment. Name-calling can be viewed as a form of fighting words. Most people have been sensitized about the impact of the words "fag" or "nigger" or the phrase "jewed down." It's not too difficult to imagine the anger a woman feels when she hears another person say, "What a dumb bitch." Language does have power. Fighting words inspire an intense emotional response that at worst leads to violence and bloodshed. All freedoms are limited because with freedom comes responsibility. Essentially, the ground rules enforce good debating practices by systematically avoiding the use of such argumentatively fallacious practices as over-broad generalizations, ad hominem attacks, and so on.

The fundamental assumption that people are doing the best they can, as stated in the ground rules, promotes an attitude of respect for each other as individuals. With mutual respect as the prevalent attitude, discussants avoid the pitfalls of name-calling and slur-slinging. Feedback from students in classes at the University of Minnesota, Duluth (UMD), where these ground rules have been implemented, shows that students feel invited to offer their own points of view in class discussions guided by ground rules. A typical statement from a student in a UMD journalism class of 168 students was: "I really like 
our class discussions. It makes me feel as though I have something important to say." When students feel safe, the floodgates open for more diverse expression. Articulating personal positions empowers people. Allowing the use of hurtful, hateful names and myths/mis-information empowers some at the expense of others. The ground rules help establish a classroom climate of equity, but they alone do not go far enough in the pursuit of engendering student activity and involvement.

\section{Putting Equitable Learning Strategies into Action}

In addition to creating a safe environment by establishing ground rules, faculty can employ active learning strategies which pay particular attention to student communication patterns. Faculty members might try one or two of the following techniques if they are not already using them.

- Teachers must be consciously aware of the communication patterns which are encouraged in their classrooms.

To become aware, a teacher may want to ask a colleague or an instructional development consultant to observe in-class behavior. Are gender runs present? Are students interrupting one another? Are just a few students dominating the discussion? How long is a given student's response?

To facilitate the recording of communication patterns in classrooms, the instructor should provide the observer with a sketch of the classroom, with students identified by name if possible. The professor, together with the consultant, should develop a code to identify the types of interactions (?=student asks question; ? $\mathrm{R}=$ student responds to teacher question; $\mathrm{SC}=$ student comments on previous statement; SI=student offers additional information; etc.). The consultant, or other observer, can then number the order of interactions and indicate gender or other identifiers if no seating chart is available.

Once one becomes aware of the patterns used in the classroom and desires to change them, a useful tool, which was shared by Krupnick at a Harvard workshop (1991), is the tic-tac-toe approach. 
The teacher merely draws the tic-tac-toe board on a piece of paper, keeping handy throughout the class. As discussion occurs, the teacher and a possible observer record the order of the students' responses with a specific reference to gender. As the teacher facilitates the class, responses by gender or other classification should be alternated proportionately to the classroom population. By changing the location of the responses in the classroom, one is more likely to capture and hold students' attention.

For example, if one is teaching in a large lecture hall, one might divide the classroom into nine sectors similar to that of a tic-tac-toe game pattern. After posing a question and waiting a sufficient time for the students to process the question, the teacher might look for a respondent in the lower left-hand sector. If a female responds, an F1 is recorded in the sector. After waiting for students to process the next question, the teacher might then seek a response from a male student in the upper-middle sector. Hearing a variety of voices is the purpose, so if the first responder were a white female, the teacher might then look for a male person of color to respond next. The next person called upon might come from the center-middle sector and be a differently abled female. It is a relatively simple matter to equalize participation by calling on students in nonadjacent blocks. This sequence of responses is recorded on figure 1.

\section{FIGURE 1}

\begin{tabular}{l|c|c} 
M5 & M2 & F8 \\
\hline & F3 & M6 \\
\hline F1 & M7 & F4
\end{tabular}

An instructor can easily record this sequence while discussing course content. Keeping track of this sequencing enables many more 
student voices to be heard, and the teacher has a convenient visual record of what is happening on the classroom playing field.

If the teacher does not know the students by name, from the first day of class the instructor might have them preface their responses or remarks by stating their names. Faculty members can make a mental note of each name, repeating it to themselves and making an effort to connect the name with the face. It is amazing how much this technique enhances community; the students not only introduce themselves to the teacher but also to each other. (This technique works in many group settings. Readers are encouraged to try it when presenting at a national conference.)

- The truth of the matter, however, is one becomes a much better facilitator of equitable education in classrooms if one learns students' names.

Teachers can equalize contributions by being able to direct response patterns. "Hey, you've said enough" is not as conducive to learning as "Jack, we appreciated your input during the last class. Now, Mary, what did you think about Jack's idea...?"

Using computer-generated or student-written nameplates propped on the desk is yet another aid to both teacher and students in learning everyone's name. By helping students become acquainted, the teacher is increasing the chance of extending the learning community beyond the classroom. The Harvard Assessment Seminar First Report (1990, p. 21) shows that many students may well learn more outside of the classroom than in it, so it pays to help them network. (Caution: Faculty should not become nameplate dependent; nameplates are just a temporary tool to help learn names.)

Of course, faculty can use UMD literature teacher Steve Adam's idea of taking Polaroid "family" portraits the first day of class. As the pictures develop, students write their names on their group picture and attach their completed personal information sheets. Adams studies the information sheets and the pictures to enable him to call each of 80 by name by the end of Week One. Another UMD faculty member, Helen Rallis, Education, astonishes her class on the second day by addressing each student by name. The first day Rallis has all students introduce 
themselves on videotape, telling something memorable about themselves, such as where they are from, and so forth. Before the next class, she reviews the tape until she can name each student.

It is much easier to hear all students' voices if the teacher knows who the students are and can modulate participation patterns by calling on them. In addition, this technique allows the teacher to more readily control gender and dominant group runs. And, the teacher will no longer be dependent upon the students who volunteer. Many teachers get superficial responses by calling on those first waving hands. Yes, there are shy students, but all should be ready to comment on assigned reading. Students are more reticent in large classes, so teachers must patiently persevere. If the teacher does not speak, a student eventually will. If the professor relies on a few eager volunteers for several class periods in a row, a communication pattern develops which stifles the less eager, potentially more analytical responders. As a classroom facilitator, instructors must ignite the desire to learn by providing opportunities for all students to vocalize and own the material being explored.

As the class progresses, one might try a method UMD's Charlotte MacLeod, Women's Studies and Medical School, uses. The teacher poses a question or makes a statement for discussion and then calls on a student. Once that student has spoken, the student calls on the next person to speak. If the teacher wants to reenter the discussion, she must also be called on by the previous speaker. This is a difficult practice for some teachers to put into action because they feel they are relinquishing control. The feeling of loss is more than made up for - by the variety and quality of student responses - when this technique is effectively used. Students do want to hear what other students have to say; students do learn from each other.

- An excellent and time-efficient device to get feedback and to hear student voices is K. Patricia Cross's "One Minute Paper."

In essence, the teacher stops class two or three minutes before the time expires and has students anonymously answer:

1) What is the big point you learned in class today? 
2) What are the main unanswered questions you leave class with today? (Light, 1990, p. 36)

Professor Frederick Mosteller, when teaching a basic statistical methods class at Harvard, extended Cross's idea. He decided to summarize briefly the answers to those two questions and distribute them in class the next day (Light, p. 37). His students could hear each other's voices and get a sense of how they were doing in relationship to other students. In addition, they had a record of what they were learning.

- The professor's classroom demeanor, how the teacher structures activities, and the instructor's body language speak volumes to students.

If teachers ask a question during a lecture, it should not be allowed to become unintentionally rhetorical. The teacher should WAIT. Professors should actually count to 5 or 10 and walk about the room, not looking at the students but giving them freedom to think as the teacher's body language tells them that he or she is patiently awaiting a reply. If one can tolerate the silence, an answer will be forthcoming. If the teacher nods, shows receptivity to the ideas expressed, and does not comment, it is quite likely a student will respond to the first student's statement; a dialogue among students often ensues. These voices, the teacher's and the students', can be heard only if the teacher intentionally orchestrates effective communication patterns in the classroom.

- As mentioned previously, exercise design is crucial in promoting equitable participation.

Incorporating a few of the following suggestions can help broaden the participation base of the classroom:

- Focus students' thoughts by having them anonymously write for a few minutes on a given topic. Collect and randomly distribute the papers. Hear all the voices by having each student read the paper in hand. This technique jump starts discussion. (In reality, this is pretty tough to do in a class where there are 200 students, so a variation of this is: Each student does a three-minute discov- 
ery writing. Five students are assigned to a group. This group of five gives another group its papers, and each group reads the responses of the other group's members. This is used as a basis for discussion.) Using other people's ideas as starters enables students to express themselves more freely.

- Have small groups record on newsprint the ideas they have generated. Taping their newsprint sheets to the wall surrounds the class with a product - their own.

- Eliminate repetition and save time in small group reports by having groups check off and not restate duplicate ideas.

- Have students share a lesson learned, discuss a point, or reach a conclusion with a neighboring student in the classroom.

Incorporating all of the above elements into the design of classroom activities enables the teacher to hear a choir of student voices, each singing its own distinctive part.

- Listen.

When students begin statements in class, teachers should not assume they know what the students are going to say. Teachers should not cut off the students; rather, they should listen and reflect. One never knows - another student may respond if the teacher is not talking. Alternatively, instructors might choose to facilitate discussion by repeating what the students have said. This technique allows the faculty members to check that what they think the student said is actually what the student intended to say. It also broadcasts students' ideas from one sector of the classroom to other sectors (sometimes students' voices do not carry).

To hear all students' voices, teachers must, if they have not already done so, transform their teaching and become practitioners of interactive strategies which promote equal coeducation in higher education.

\section{Conclusion}

Remember: It doesn't matter who wins; it's how one plays the game. But the coach is the one who decides who plays. The teacher, 
the coach of the educational team in the classroom, has the responsibility to work with team members to give all voices an airing; to facilitate the redistribution of power; to generate equitable, agreed upon ground rules; and to implement active teaching and learning strategies. The playing field then becomes level for all to achieve their personal bests.

\section{References}

Cannon, L.W. (1990). Fostering positive race, class, and gender dynamics in the classroom. Women's Studies Quarterly 1990: 1 \& 2, 126-134.

Hilsen, L.R. (1992, Spring). Transforming teaching: Hearing all the voices. Instructional Development, 3, 6-8.

Krupnick, C.G. (1985). Women and men in the classroom: Inequality and its remedies. Teaching and Learning, 1(1), 18-25.

Krupnick, C.G. (1991, March). Learnings from co-education: Issues and research on women and men on campus. Session presented at the Harvard University Graduate School of Education Conference on Women and Men on Campus: Inequality and Its Remedies, Cambridge, MA.

Light, R.J. (1990). The Harvard assessment seminars first report, 1990: Explorations with students and faculty about teaching, learning, and student life. Cambridge, MA: Harvard University Graduate School of Education and Kennedy School of Government.

Parlee, M.B. (1989). Conversational politics. In L. Richardson \& G.V. Taylor (Eds.), Feminist frontiers II: Rethinking sex, gender, and society (pp. 10-14). New York: Random House.

Petersen-Perlman, D.S. (1992, Winter). The safe classroom. Instructional Development, $6,8$.

Sadker, M., \& Sadker, D. (1990, November-December). Sexism in the classroom: From grade school to graduate school. Association for Women in Mathematics Newsletter, 11-14. 